\title{
Ovarian carcinomas, including secondary tumors: diagnostically challenging areas
}

\author{
Jaime Prat \\ Department of Pathology, Hospital de la Santa Creu i Sant Pau, Autonomous University of Barcelona, Spain
}

\begin{abstract}
The differential diagnosis of ovarian carcinomas, including secondary tumors, remains a challenging task. Mucinous carcinomas of the ovary are rare and can be easily confused with metastatic mucinous carcinomas that may present clinically as a primary ovarian tumor. Most of these originate in the gastrointestinal tract and pancreas. International Federation of Gynecology and Obstetrics (FIGO) stage is the single most important prognostic factor, and stage I carcinomas have an excellent prognosis; FIGO stage is largely related to the histologic features of the ovarian tumors. Infiltrative stromal invasion proved to be biologically more aggressive than expansile invasion. Metastatic colon cancer is frequent and often simulates ovarian endometrioid adenocarcinoma. Although immunostains for cytokeratins 7 and 20 can be helpful in the differential diagnosis, they should always be interpreted in the light of all clinical information. Occasionally, endometrioid carcinomas may exhibit a microglandular pattern simulating sex cord-stromal tumors. However, typical endometrioid glands, squamous differentiation, or an adenofibroma component are each present in $75 \%$ of these tumors whereas immunostains for calretinin and alpha-inhibin are negative. Endometrioid carcinoma of the ovary is associated in $15-20 \%$ of the cases with carcinoma of the endometrium. Most of these tumors have a favorable outcome and they most likely represent independent primary carcinomas arising as a result of a Müllerian field effect. Although the criteria for distinguishing metastatic from independent primary carcinomas rely mainly upon conventional clinicopathologic findings, loss of heterozygosity and gene mutation analyses can be helpful. Transitional cell carcinomas are distinguished from undifferentiated carcinomas by the presence of thick, undulating papillae with smooth luminal borders, microspaces, and tumor cells with distinctive 'urothelial' appearance. Krukenberg tumors are metastatic adenocarcinomas traditionally perceived as composed of mucin-filled signet-ring cells associated with a striking proliferation of the ovarian stroma but many variations on this pattern occur.
\end{abstract}

Modern Pathology (2005) 18, S99-S111. doi:10.1038/modpathol.3800312

Keywords: ovary; carcinomas; mucinous; endometrioid; transitional; metastatic carcinomas

In this presentation, eight different categories of primary and metastatic epithelial ovarian tumors that often pose a diagnostic challenge will be discussed (Figure 1).

\section{Mucinous carcinomas}

Over the last 30 years, the establishment of the borderline subcategory of mucinous tumors, the increasing recognition of metastatic adenocarcinomas that resemble primary ovarian mucinous tumors, and the interpretation of most ovarian mucinous cystic tumors associated with pseudomyxoma peritonei as metastatic tumors from the

Correspondence: Dr J Prat, MD, FRC Path, Department of Pathology, Hospital de la Santa Creu i Sant Pau, Sant Antoni M. Claret 167, 08025 Barcelona, Spain.

E-mail: jprat@santpau.es

Received and accepted 30 August 2004 appendix have reduced significantly the number of mucinous ovarian tumors currently diagnosed as carcinoma (Figure 2). Thus, for such tumors, the reported frequency of $15 \%$ is almost certainly an overestimation, and most recent studies have been based on a relatively small number of cases.

The tumors are bilateral in only $5 \%$ of the cases. Bilateral mucinous carcinomas or unilateral carcinomas $<10 \mathrm{~cm}$ in greatest dimension should raise the suspicion of metastasis. ${ }^{1}$ Over $80 \%$ of frankly invasive mucinous carcinomas have components of mucinous borderline tumor or mucinous cystadenoma or both, suggesting a progression from benign to malignant neoplasia and indicating the importance of extensive sampling as the malignant areas may involve only a small portion of the tumor. Recently, it has been proposed to divide mucinous carcinomas into two categories: an expansile type without demonstrable destructive stromal invasion, 
1. Mucinous carcinomas

2. Mural nodules in mucinous cystic tumors

3. Metastatic mucinous carcinomas

4. Metastatic colon cancer of non-mucinous type

5. Endometrioid adenocarcinomas simulating sex cord-stromal tumors

6. Simultaneous endometrioid carcinomas of ovary and uterus

7. Malignant Brenner tumor and transitional cell carcinoma

8. Krukenberg tumor

Figure 1 Ovarian carcinomas, including secondary tumors: diagnostically challenging areas.

\section{Mucinous Tumors of the Ovary \\ (From benign to malignant)}

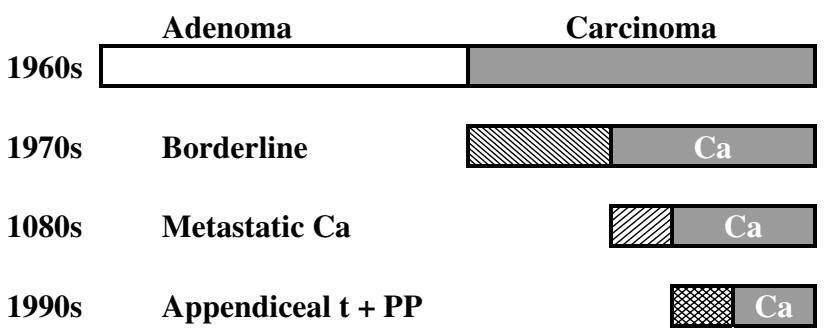

Figure 2 Mucinous carcinomas. Over the last decades, the rate of ovarian carcinomas diagnosed as primary mucinous carcinomas (Ca) has been progressively reduced because of the introduction of the borderline category of tumors; the segregation of metastatic adenocarcinomas, particularly of the large intestine and pancreas, that simulate primary ovarian tumors; and the finding that most mucinous ovarian tumors associated with 'pseudomyxoma peritonei' (PP) are secondary neoplams, often from the appendix.

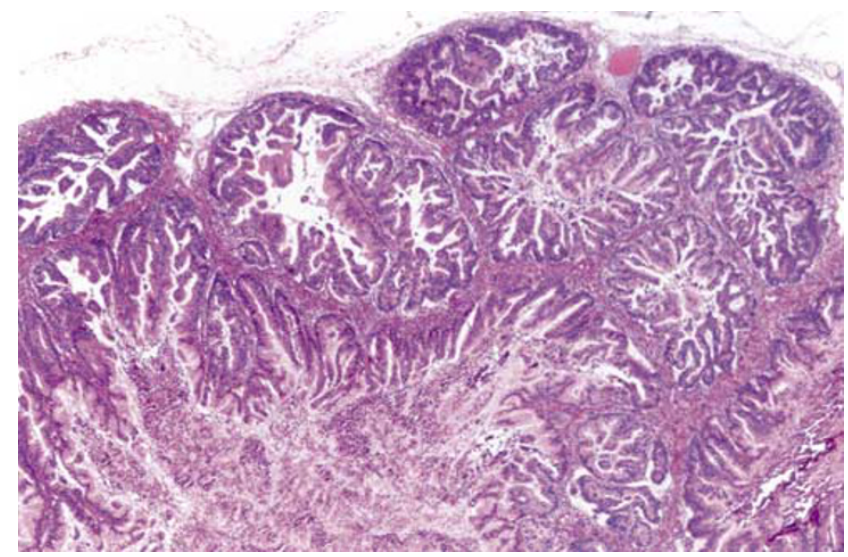

Figure 3 Mucinous carcinoma with expansile invasion. Confluent, complex glandular proliferation without obvious stromal invasion (Figure 7-18 from Prat J. Pathology of the Ovary. Saunders: Philadelphia, 2004). Reproduced with permission.

but exhibiting back-to-back or complex malignant glands without or with minimal intervening stroma and exceeding $10 \mathrm{~mm}^{2}$ in area ( $>3 \mathrm{~mm}$ in each of two linear dimensions) (Figure 3); and an infiltrative type, characterized by obvious stromal invasion in

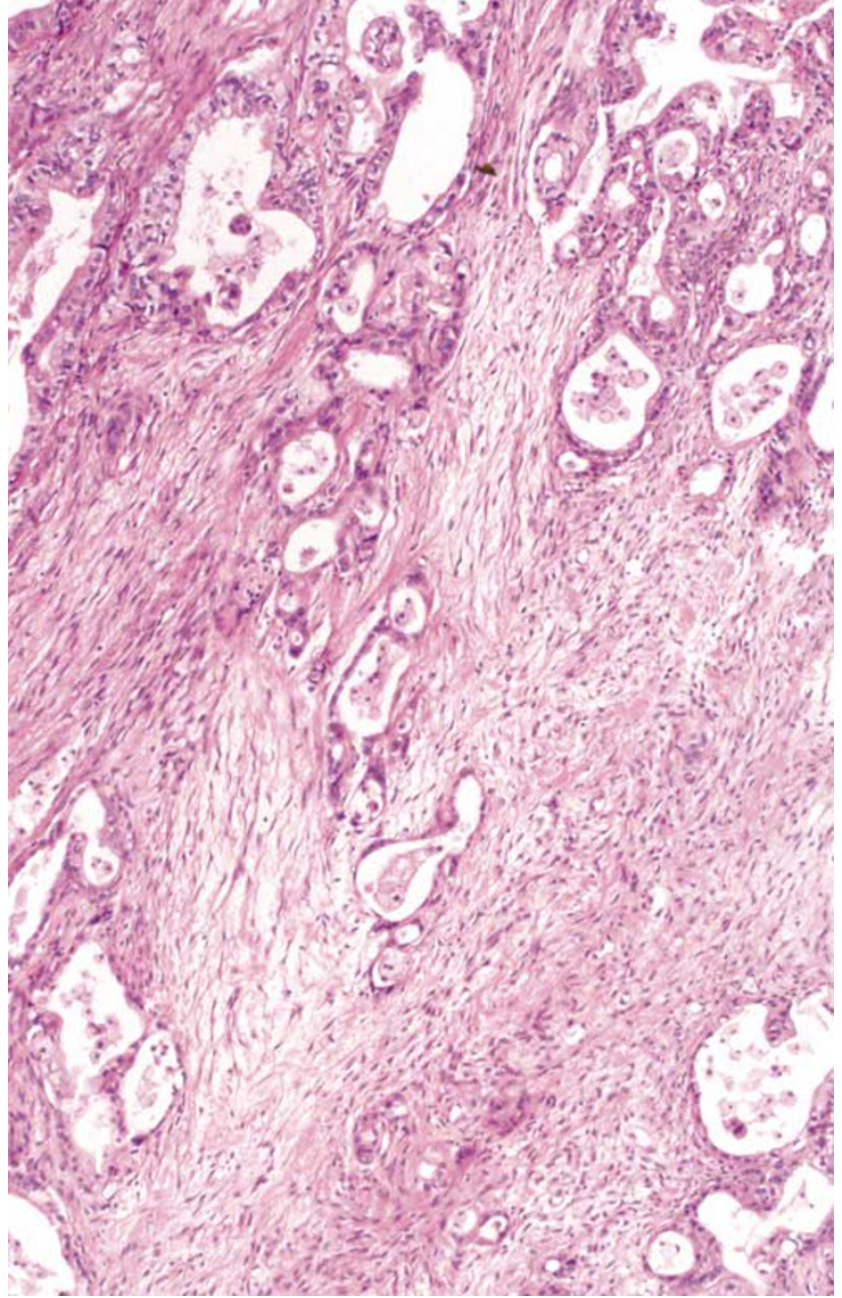

Figure 4 Mucinous carcinoma with infiltrative invasion. Mucinous glands infiltrate a desmoplastic stroma (Figure 7-22 from Prat J. Pathology of the Ovary. Saunders: Philadelphia, 2004). Reproduced with permission.

the form of glands, cell clusters, or individual cells, disorderly infiltrating the stroma and frequently associated with a desmoplastic stromal reaction (Figure 4). ${ }^{2}$ The expansile pattern of growth has also been referred in the literature as the 'noninvasive', 'intraglandular'3 or 'confluent glandular's pattern.

Rare mucinous carcinomas of the endocervicallike or mixed Müllerian type have been described recently; ${ }^{5,6}$ three of these cases were associated with endometriosis and one with an endocervical-like mucinous borderline tumor of the contralateral ovary. ${ }^{6}$

\section{Differential Diagnosis}

The most important differential diagnosis of mucinous ovarian carcinoma is with metastatic mucinous carcinoma that may present clinically 
as a primary ovarian tumor. Most of these originate in the large intestine, appendix, pancreas, biliary tract, stomach, or cervix..$^{7-11}$ Common features that favor a primary mucinous carcinoma are an expansile pattern of invasion and a complex papillary pattern (Figure 3). ${ }^{11}$ Features favoring a metastatic mucinous carcinoma include bilaterality, a multinodular growth pattern microscopically, ovarian surface involvement by epithelial cells (surface implants) (Figure 5), and vascular space invasion. Extensive intra-abdominal spread of tumor, although sometimes seen with primary mucinous tumors, should always cause suspicion for a tumor metastatic to the ovary. ${ }^{11}$

\section{Somatic Genetics}

As indicated above, tumor heterogeneity is common and probably reflects the progression from benign to malignant neoplasia that often occurs in mucinous carcinogenesis. Recent studies have strongly suggested that in the sequence of malignant transformation from benign and borderline mucinous tumors to infiltrative carcinoma, intraepithelial (noninvasive) carcinomas and carcinomas with purely expansile (not obvious) invasion represent transitional stages of mucinous carcinogenesis. $^{2,12}$ This hypothesis is also supported by the results of recent investigations of the genetic alterations occuring in ovarian mucinous tumors. ${ }^{13-15}$ An increasing frequency of codon 12/13 K-ras mutations in benign, borderline tumors, and carcinomas has been reported, supporting that K-ras mutational activation is an early event in mucinous ovarian tumorigenesis (Figure 6). ${ }^{13-15}$ Using microdissection, we have detected the same K-ras mutation in separate areas exhibiting different histological grades within the same neoplasm in 15 mucinous tumors. ${ }^{14}$

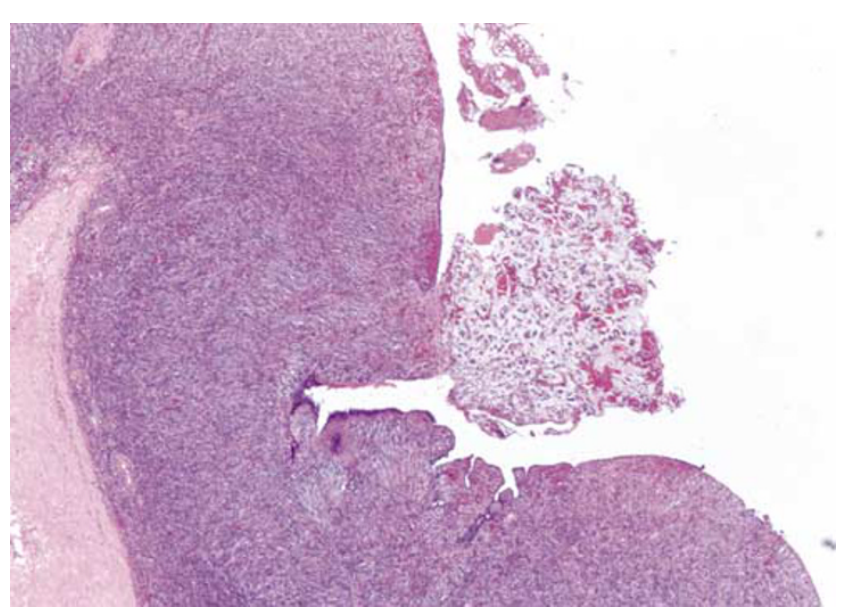

Figure 5 Metastatic mucinous adenocarcinoma from colon. Ovarian surface involvement by mucinous epithelial cells (surface implants). (Figure 18-9 from Prat J. Pathology of the Ovary. Saunders: Philadelphia, 2004). Reproduced with permission.

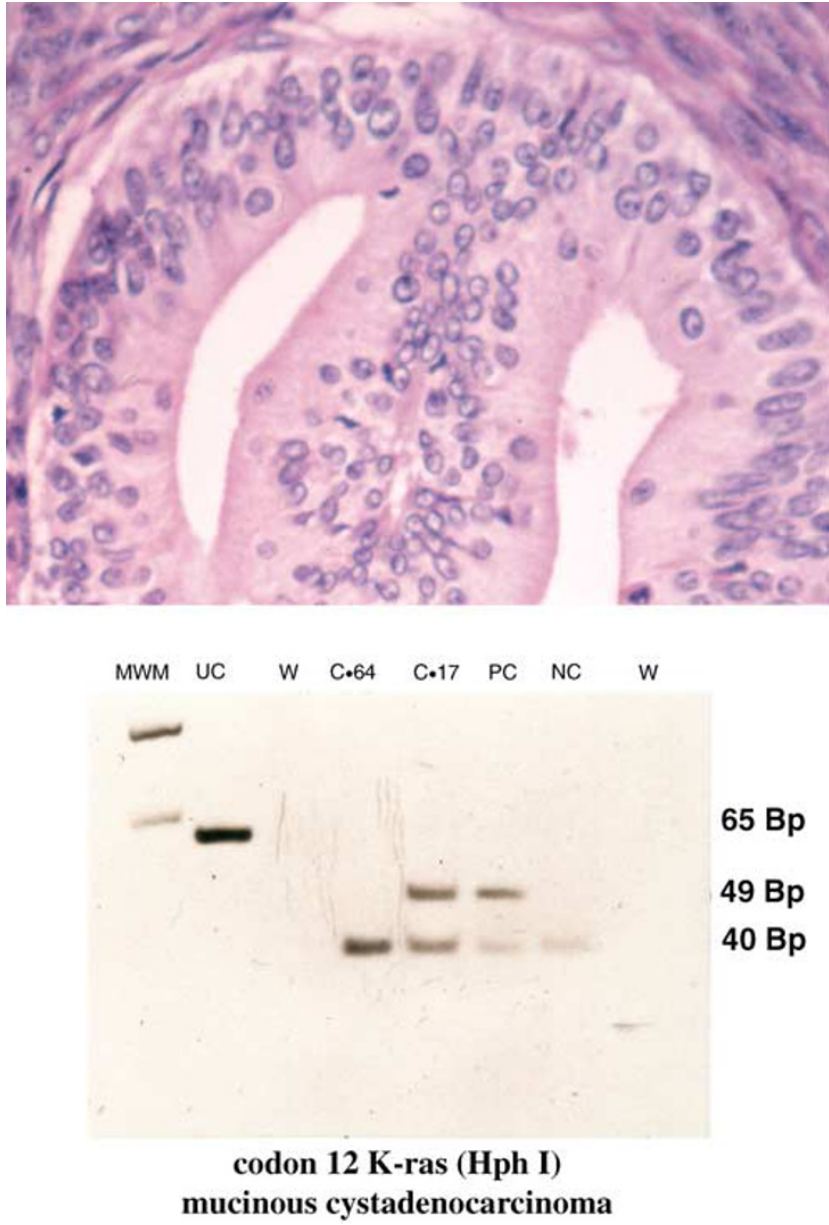

Figure 6 Well-differentiated mucinous carcinoma. RFLP-PCR analysis shows a point mutation at codon 12 of $K$-ras (Case 17). The 49- and 40-bp bands correspond to the mutant and normal alleles, respectively. Note that both the positive control (PC) and the investigated tumor (C-17) are heterozygous and show two bands (Figure 7-27 from Prat J. Pathology of the Ovary. Saunders: Philadelphia, 2004). Reproduced with permission.

\section{Prognosis}

International Federation of Gynecology and Obstetrics (FIGO) stage is the single most important prognostic factor, and stage I carcinomas have an excellent prognosis; however, the prognosis in cases with extraovarian spread is very poor. ${ }^{2-4,12,16}$ Recent studies have clearly demonstrated that FIGO stage is largely related to the histologic features of the ovarian tumors. Infiltrative stromal invasion proved to be biologically more aggressive than expansile invasion. In two recent series totaling 59 cases of invasive carcinoma, ${ }^{2,12}$ all 20 cases of carcinoma with expansile invasion and follow-up information were stage I and none of the patients had recurrent disease. Of the 25 infiltrative carcinomas with follow-up data, only nine of 13 patients with stage I disease and one of 12 with higher-stage disease (stage IIA) had a favorable outcome. Furthermore, in contrast to previous reports,,$^{2-4}$ one of the two 
series $^{12}$ showed that high nuclear grade (grade 3 ) was predictive of behavior independent of the surgical stage.

The combination of extensive and infiltrative stromal invasion, high nuclear grade, and tumor rupture should be considered a strong predictor of recurrence for stage I mucinous carcinomas. ${ }^{12}$

Foci of stromal invasion $<10 \mathrm{~mm}^{2}$ have been designated 'microinvasive,' and cases with such finding have had a favorable outcome. ${ }^{2,12}$ However, experience with these tumors is limited, and occasional carcinomas with stromal invasion barely beyond the limit accepted for microinvasion have produced metastases. ${ }^{16}$

\section{Mural nodules in mucinous cystic tumors}

Mucinous cystic tumors of the ovary, whether benign, borderline, or malignant, may contain one or more mural nodules that differ notably in their microscopic features from those of the underlying mucinous neoplasm. The nodules have been classified into three major subtypes: (a) sarcoma-like mural nodules; (b) nodules of anaplastic carcinoma; and (c) sarcoma. ${ }^{17-20}$ However, mixed nodules have also been described. ${ }^{21}$

Sarcoma-like mural nodules occur predominantly in middle-aged women (mean age, 39 years) as redbrown nodules $(0.6-6 \mathrm{~cm}$ in diameter), which appear sharply demarcated from the adjacent mucinous epithelium (Figure 7). They are associated with mucinous carcinomas in about half the cases and with benign and borderline mucinous tumors in the remainder. The nodules are almost always multiple. They exhibit a heterogenous cell population characterized by numerous multinucleated cells of the epulis type, atypical spindle cells, and inflammatory cells (Figure 8). In some nodules, the predominant elements are spindle-shaped cells of moderate size containing hyperchromatic nuclei and pleomorphic mononucleated or binucleated giant cells. The mitotic index in the most cellular areas range from 5 to 10 per 10 high power fields (HPF). Immunohistochemical staining shows positivity for histiocyte markers and vimentin, with weak and focal staining for cytokeratins (CKs), suggesting a possible origin from submesothelial mesenchymal cells ${ }^{20}$ possibly stimulated to proliferate as a result of spillage of mucin or hemorrhage into aggregates of these cells within the ovary. All of the lesions that have been accurately diagnosed have had a benign clinical course. ${ }^{20}$ The nodules of anaplastic carcinoma are characterized by either a diffuse collection of large rhabdoid cells with abundant eosinophilic cytoplasm, eccentric nuclei, and one or more prominent nucleoli (Figure 9); sarcomatoid spindle cells with atypical and vesicular nuclei often exhibiting a herringbone pattern; or pleomorphic cells. $^{22}$ CK immunostaining is usually strongly positive. These lesions are found almost always in

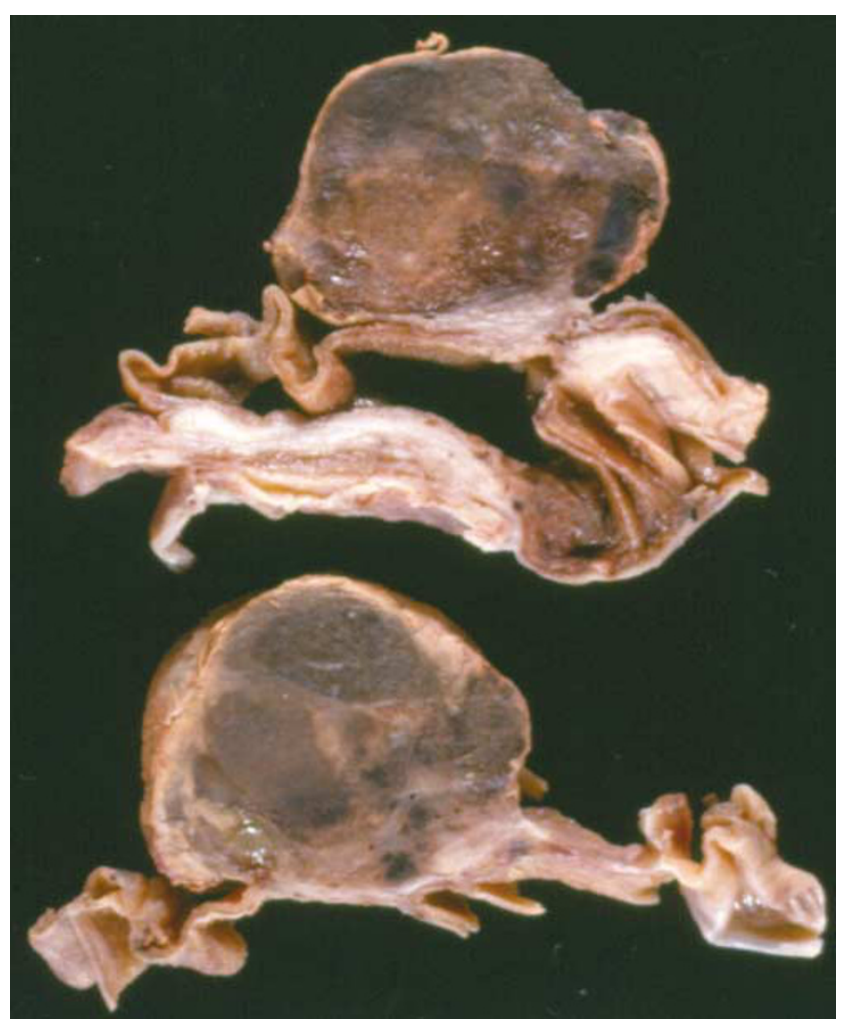

Figure 7 Sarcoma-like mural nodules in a mucinous cystic tumor. The sectioned surfaces show two hemorrhagic nodules that appear well-circumscribed (Figure 26 from Prat J. Ovarian tumors of borderline malignancy (tumors of low malignant potential): a critical appraisal. Adv Anat Pathol 1999;6:247-274). Reproduced with permission of Lippincott, Williams \& Wilkins.

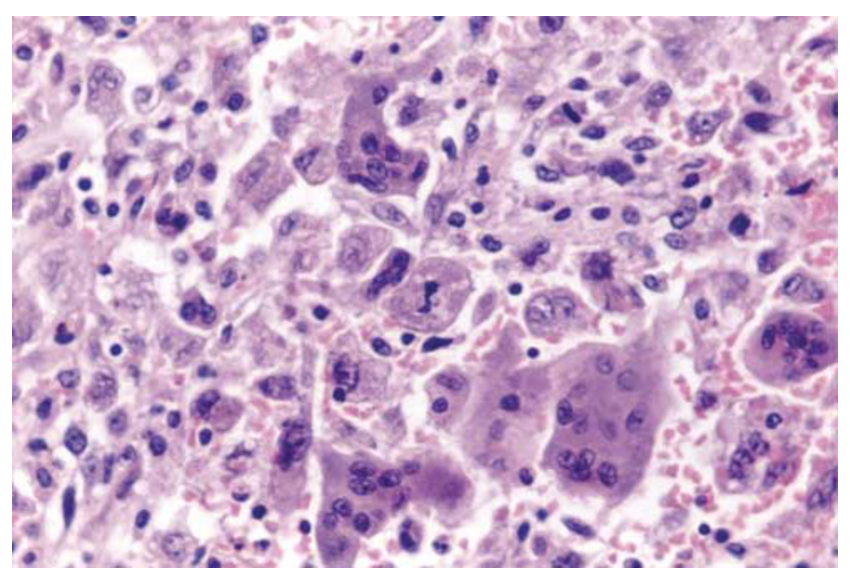

Figure 8 Sarcoma-like mural nodule in a mucinous cystic tumor. The cells of the nodule include osteoclast-like giant cells and smaller mononuclear cells. Two atypical mitotic figures are present (Figure 7-35 from Prat J. Pathology of the Ovary. Saunders: Philadelphia, 2004). Reproduced with permission.

malignant or borderline mucinous tumors, and very rarely in cystadenomas. Their size range from microscopic to about $10 \mathrm{~cm}$. They may be single or multiple. Frequently, there is invasion of the surrounding tissue and, in a minority of cases, 

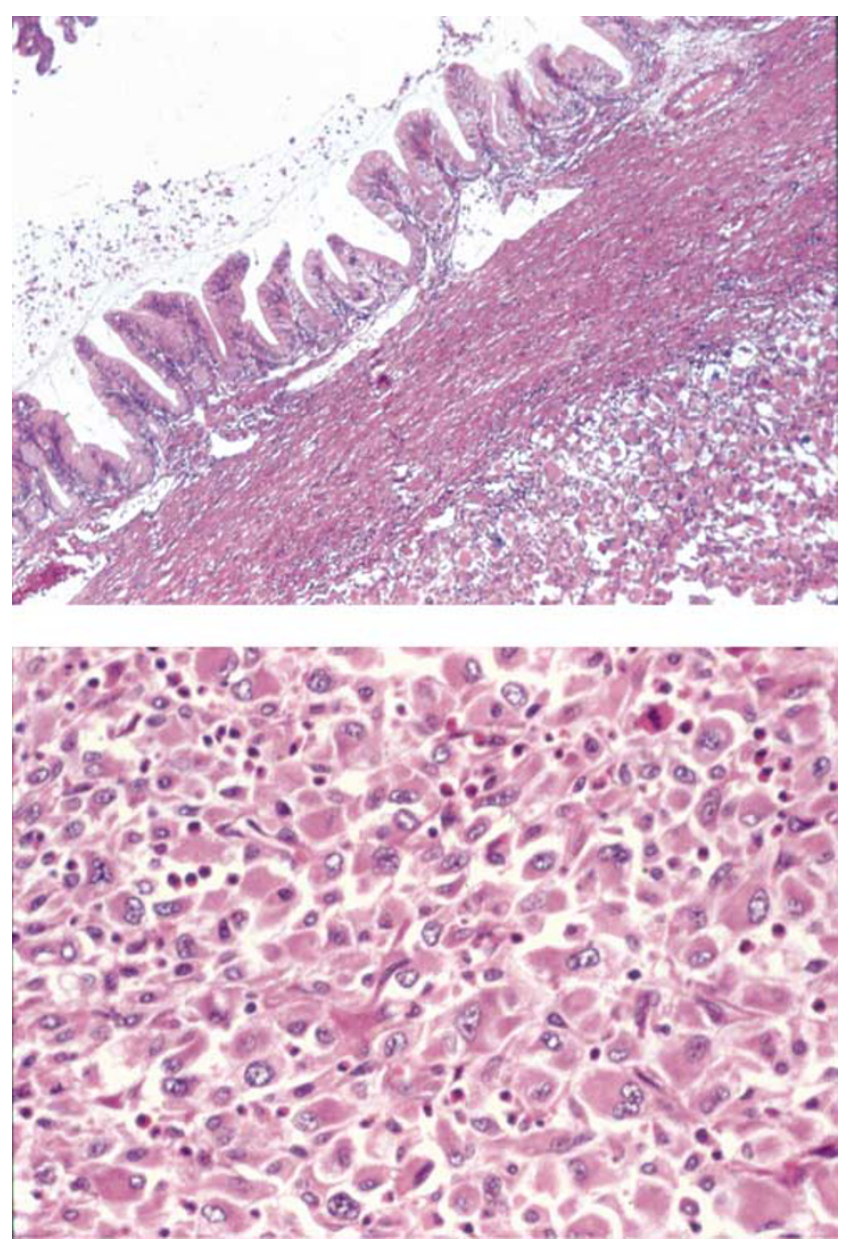

Figure 9 Anaplastic carcinoma in mucinous cystic tumor. The epithelial lining of the cyst appears as borderline malignancy (top). The undifferentiated component is characterized by a diffuse arrangement of cells with abundant eosinophilic cytoplasm and grade 3 nuclei (Figure 7-38 from Prat J. Pathology of the Ovary. Saunders: Philadelphia, 2004). Reproduced with permission.

vascular space invasion as well. ${ }^{18}$ Although they were first thought to carry an invariably unfavorable prognosis, recent data indicate that this does not necessarily apply to those found within unruptured stage I mucinous cystic tumors. ${ }^{12,22}$

Various types of true sarcomatous nodules have been reported, such as fibrosarcoma, rhabdomyosarcoma, and undifferentiated sarcoma. These tumors are associated with poor prognosis. Mixed nodules consist of usually small foci of anaplastic carcinoma within what appears to be a sarcoma-like mural nodule. Also, in tumors containing multiple nodules, some of them may be of one type and others of another type. ${ }^{20}$

\section{Metastatic mucinous carcinomas}

Mucinous tumors metastatic to the ovary may resemble primary ovarian tumors both grossly and

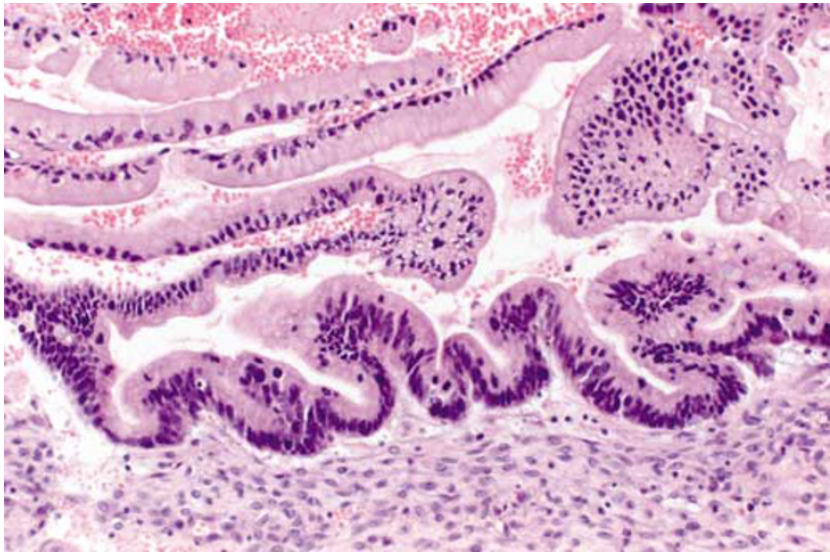

Figure 10 Metastatic mucinous adenocarcinoma of the pancreas to the ovary. The tumor resembles a benign and borderline primary mucinous ovarian tumor (Figure 20 from Prat J. Ovarian tumors of borderline malignancy (tumors of low malignant potential): a critical appraisal. Adv Anat Pathol 1999;6:247274). Reproduced with permission of Lippincott, Williams \& Wilkins.

microscopically. The metastases may be moderately differentiated or so well differentiated that they can be mistaken for mucinous borderline tumors even with foci that appear benign (Figure 10). The primary tumors are usually in the large intestine, stomach, pancreas, or biliary tract. In addition to exhibiting the general features of metastatic tumors to the ovary (see above), these tumors are characterized by irregular infiltrative growth with desmoplasia, single cell invasion, signet-ring cells, and surface mucin. ${ }^{11}$ Thorough sampling is crucial in identifying sometimes minor or major diagnostic clues.

\section{Immunohistochemistry}

Immunohistochemical stains can be helpful in distinguishing primary ovarian adenocarcinomas from metastatic carcinomas of the digestive system (Table 1). CK immunostains are the most commonly used. Primary ovarian carcinomas are almost always immunoreactive for CK7 whereas colorectal adenocarcinomas are usually CK7 negative. ${ }^{23,24}$ Mucinous adenocarcinomas of the ovary may be immunoreactive for CK20, but the reaction is typically weak and focal. ${ }^{9,23}$ Endometrioid adenocarcinomas are almost invariably CK20 negative. ${ }^{24}$ In contrast, colorectal adenocarcinomas are diffusely and strongly reactive for CK20. Therefore, a CK7-positive/CK20-negative immunoprofile favors a primary ovarian carcinoma, whereas a CK7-negative/CK20-positive suggests metastatic adenocarcinoma. ${ }^{9,25,26}$ Although the vast majority of colorectal adenocarcinomas express CK20, poorly differentiated and right-sided tumors can be CK20 negative. ${ }^{10}$ Furthermore, adenocarcinomas of the appendix, small intestine, and stomach 
Table 1 Primary ovarian carcinomas vs metastatic carcinomas from the digestive system

Tumor Immunophenotypes

CK7 CK20 CA125 MUC5AC HAM56 CEA

\begin{tabular}{|c|c|c|c|c|c|c|}
\hline \multicolumn{7}{|c|}{ Ovarian carcinoma } \\
\hline Serous & + & - & + & & + & \\
\hline Mucinous & + & + & $-1+$ & $+1-$ & + & + \\
\hline Endometrioid & + & - & + & & + & - \\
\hline \multicolumn{7}{|c|}{ Metastatic carcinoma } \\
\hline Colon-rectum & - & + & - & - & $-1+$ & + \\
\hline Stomach & + & $+1-$ & - & + & $-1+$ & + \\
\hline Appendix & $-/+$ & + & - & $+1-$ & & + \\
\hline Pancreas & + & + & - & + & - & + \\
\hline
\end{tabular}

CK7 $=$ cytokeratin $\quad 7 ; \quad$ CK20 $=$ cytokeratin $20 ;+=$ usually positive; $-=$ usually negative; $+/-=$ can be positive or negative, but often positive; $-/+=$ can be positive or negative, but often negative.

can be CK7 positive. Thus, immunostains for CK7 and CK20 should be interpreted with caution, always in the light of all clinical information, and with the understanding that no tumor shows absolute consistency in its staining with these markers.

Other immunohistochemical stains have greater overlap in their expressions and should not be used individually in this differential diagnosis. Nevertheless, after taking into account the clinicopathologic findings and the results of the CK immunostains, negative stainings for vimentin, ${ }^{27}$ CA125, gastric mucin gene MUC5 $\mathrm{AC}^{9}$ and human alveolar macrophage 56 (HAM56), ${ }^{28}$ and strongly positive staining for carcinoembryonic antigen (CEA) ${ }^{23,24}$ favor metastatic colorectal cancer over primary ovarian adenocarcinoma. Likewise, strong immunoreactivity for P53 supports the colonic origin of the neoplasm.

\section{Metastatic colon cancer of non-mucinous type}

Most intestinal metastases originate in the large intestine and, much less frequently, in the small bowel. The ovarian tumors are bilateral in approximately two-thirds of the cases (Figure 11). Smaller tumors are usually solid, whereas larger tumors are composed of friable gray, yellow, or red tissue with cysts that contain necrotic tumor, mucinous fluid, or blood. ${ }^{1,29}$

Features that help to distinguish metastatic colon cancer from endometrioid carcinoma include luminal necrotic debris ('dirty necrosis'), focal segmental necrosis of the glands (Figure 12), occasional presence of goblet cells, and the absence of Müllerian features (squamous differentiation, an adenofibromatous component, or association with endometriosis). Also the nuclei lining the glands

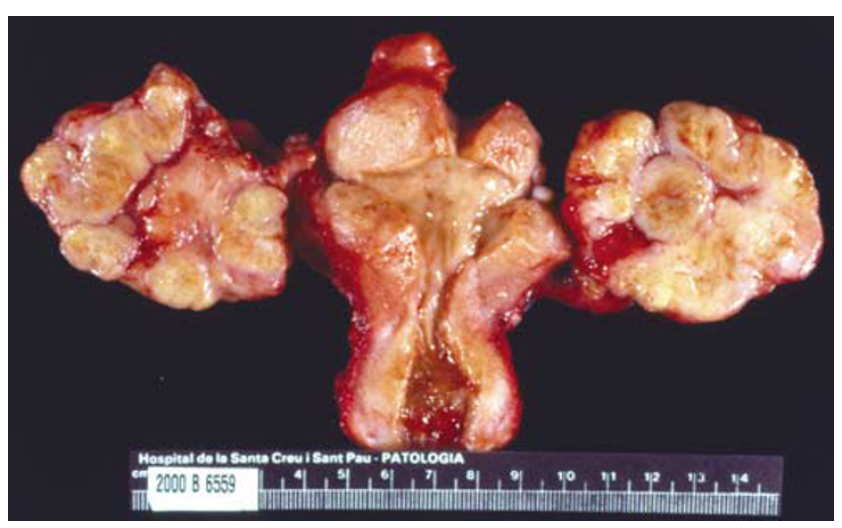

Figure 11 Metastatic adenocarcinoma from colon. The ovaries are replaced by bilateral multinodular tumor. The sectioned surfaces appear solid (Figure 18-1 from Prat J. Pathology of the Ovary. Saunders: Philadelphia, 2004). Reproduced with permission.

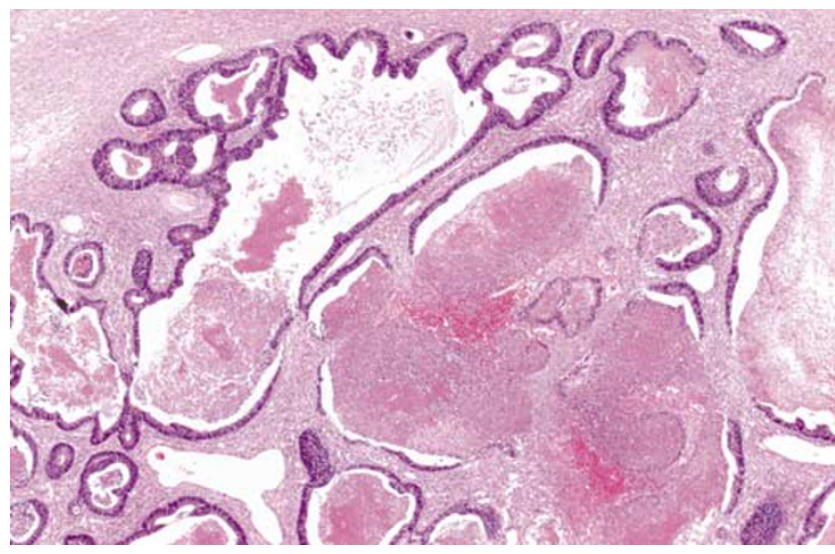

Figure 12 Metastatic adenocarcinoma from colon. There is focal segmental necrosis of glands and luminal necrotic debris ('dirty necrosis') (Figure 18-4 from Prat J. Pathology of the Ovary. Saunders: Philadelphia, 2004). Reproduced with permission.

of metastatic colon carcinoma exhibit a higher degree of atypia than those of endometrioid carcinoma. ${ }^{1,29}$ The stroma may be desmoplastic, edematous, or myxoid, but frequently resembles ovarian stroma. Stromal luteinization is most frequently found in metastatic colorectal carcinomas, and increased steroid hormone production in these patients often results in endocrine manifestations. ${ }^{1}$ Rare adenocarcinomas metastatic from the intestine may contain cells with abundant clear cytoplasm simulating either clear cell adenocarcinoma or the secretory variant of endometrioid carcinoma. ${ }^{30}$

\section{Endometrioid adenocarcinomas simulating sex cord-stromal tumors}

Occasionally, endometrioid carcinomas contain solid areas punctuated by small rosette-like glands (microglandular pattern) simulating an adult granulosa cell tumor. ${ }^{31}$ In other cases, a diffuse growth of cells in an endometrioid carcinoma may suggest the 
diffuse pattern of a granulosa cell tumor. The nuclei of endometrioid carcinomas are usually round and hyperchromatic, whereas those of granulosa cell tumors are round, oval, or angular, pale and grooved. ${ }^{31}$ In yet other cases, endometrioid carcinomas may show focal to extensive areas resembling Sertoli and Sertoli-Leydig cell tumors (Figure 13). ${ }^{31-33}$ They contain small, well-differentiated hollow tubules, solid tubules or, rarely, thin cords resembling sex cords. When the stroma is luteinized, this variant may be mistaken for a Sertoli-Leydig cell tumor, particularly in cases in which the patient is virilized (Figure 14). Nevertheless, typical glands of endometrioid carcinoma, squamous differentiation, or an adenofibroma component are each present in $75 \%$ of the tumors, facilitating their recognition as an endometrioid carcinoma. ${ }^{31}$ Furthermore, immunostains for alpha-

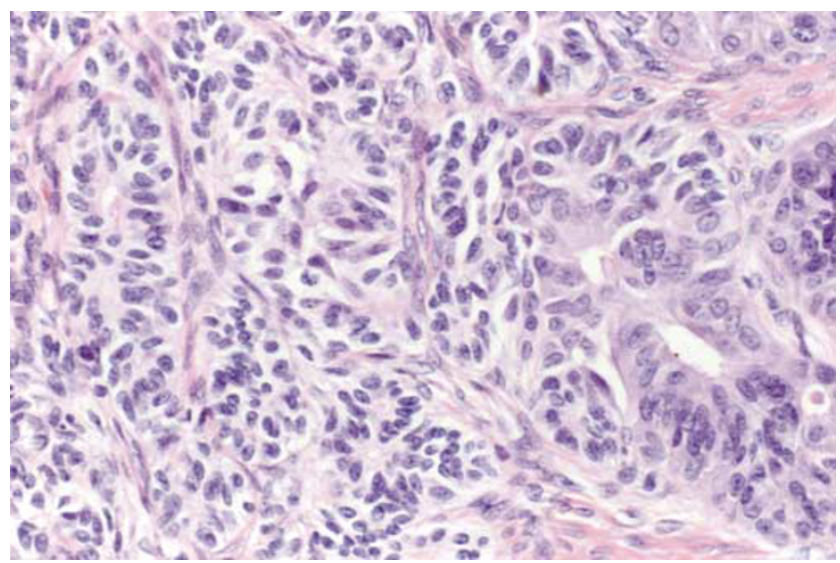

Figure 13 Endometrioid adenocarcinoma resembling a Sertoli cell tumor. Tubular glands lined by cells with oval nuclei and clear cytoplasms, resembling the tubules of a Sertoli cell tumor (left), appear adjacent to typical glands of endometrioid carcinoma (right) (Figure 8-14 from Prat J. Pathology of the Ovary. Saunders: Philadelphia, 2004). Reproduced with permission.

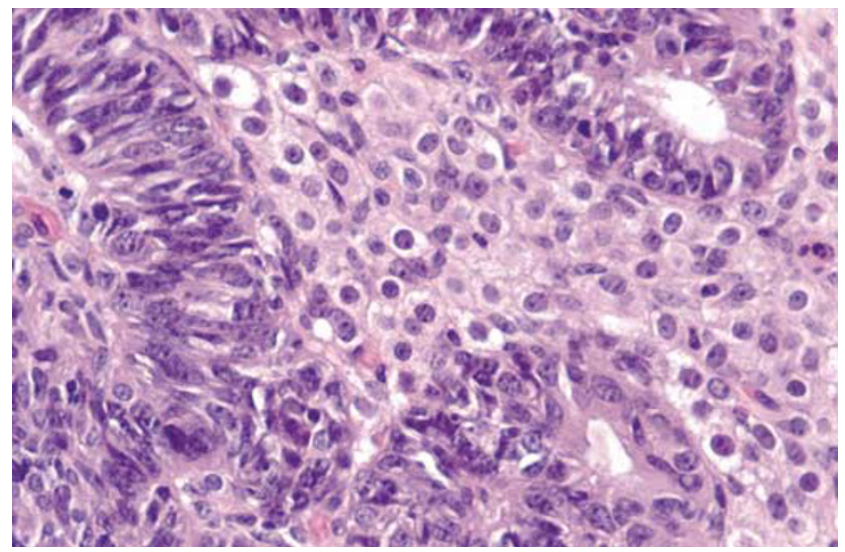

Figure 14 Endometrioid adenocarcinoma resembling a SertoliLeydig cell tumor. The tubular glands contain high-grade nuclei. The luteinized ovarian stromal cells resemble Leydig cells (Figure 8-15 from Prat J. Pathology of the Ovary. Saunders: Philadelphia, 2004). Reproduced with permission. inhibin (Figure 15) and calretinin are positive in most neoplastic granulosa and Sertoli cells but negative in the cells of endometrioid carcinoma. ${ }^{34}$ Contrariwise, positive EMA immunostains favor the diagnosis of carcinoma. ${ }^{35}$

\section{Simultaneous endometrioid carcinomas of ovary and uterus}

Endometrioid carcinoma of the ovary is associated in $15-20 \%$ of the cases with carcinoma of the endometrium. ${ }^{36-38}$ The favorable outcome in those cases in which the tumor is limited to both organs suggests that these neoplasms are mostly independent primaries arising as a result of a Müllerian field effect. $^{37,38}$ The criteria for distinguishing metastatic from independent primary carcinomas rely mainly upon conventional clinicopathologic findings, namely stage, size, histologic type and grade of the tumors, the presence and extent of blood vessel, tubal, and myometrial invasion, bilaterality, and pattern of ovarian involvement, coexistence with endometrial hyperplasia, ovarian endometriosis or adenofibroma and, ultimately, patient follow-up (Figure 16). ${ }^{1,38}$ By paying attention to these findings, the precise diagnosis can be established in most

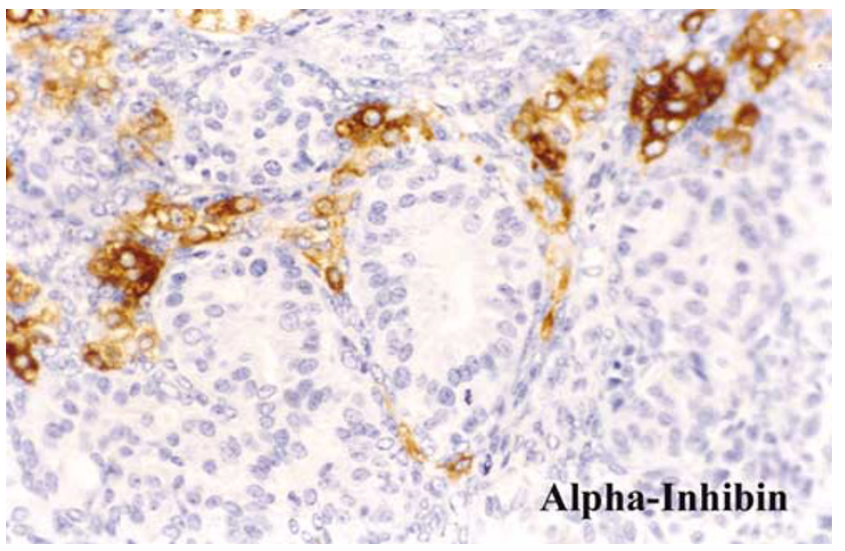

Figure 15 Endometrioid adenocarcinoma resembling a SertoliLeydig cell tumor. Immunostain for alpha-inhibin is positive in the luteinized stromal cells and negative in the epithelial cells (Figure 8-16 from Prat J. Pathology of the Ovary. Saunders: Philadelphia, 2004). Reproduced with permission.

Simultaneous endometrioid carcinomas of ovary and uterus Independent versus metastatic tumors

\begin{tabular}{|c|c|}
\hline $\begin{array}{ll}\text { - } & \text { Stage } \\
\text { - } & \text { Size } \\
\text { - } & \text { Histologic type } \\
\text { - } & \text { Histologic grade } \\
\text { - } & \text { Tubal invasion } \\
\end{array}$ & $\begin{array}{ll}- & \text { Blood vessel invasion } \\
- & \text { Bilaterality } \\
\text { - } & \text { Pattern of ovarian involv } \\
\text { - } & \text { Endometrial hyperplasia } \\
\text { - } & \text { Ovarian endometriosis } \\
\text { - } & \text { Follow-up } \\
\end{array}$ \\
\hline
\end{tabular}

Figure 16 Criteria for distinguishing metastatic from independent primary carcinomas involving the endometrium and ovaries. 
cases. In cases of endometrial carcinoma spreading to the ovaries, the latter organs usually exhibit surface involvement by multiple small tumor nodules and vascular space invasion, whereas the primary endometrial tumor often shows deep myometrial invasion and often extends through the fallopian tubes. Less frequently, an ovarian primary carcinoma produces metastasis to the endometrium. In such cases, the endomyometrial invasion may also occur as a direct extension from the ovarian tumor.

Occasionally, however, the differential diagnosis may be difficult or impossible as the tumors may show overlapping features. In these cases, immunohistochemistry is of limited value as both tumors are adenocarcinomas and may exhibit similar profiles (CK, vimentin, CEA, CA12.5, CA19.9, or betacatenin) in both circumstances. The presence of identical aneuploid DNA indexes in two separate carcinomas suggests that one of them is a metastasis from the other; and, alternatively, when the two neoplasms have different DNA indexes, the possibility of two independent primaries has to be considered. ${ }^{39}$ Nevertheless, the latter results do not exclude completely the metastatic nature of one of the two neoplasms; in fact, metastatic tumors, or even different parts of the same tumor, may exhibit DNA indexes that differ from those of their corresponding primary tumors as a consequence of tumor progression. ${ }^{40}$ Therefore, DNA cytometry is also of limited value in the differential diagnosis.

Three molecular genetic methods have been used to determine clonality in synchronous carcinomas: $\mathrm{X}$-chromosome inactivation, loss of heterozygosity (LOH), and gene mutation analyses. ${ }^{41,42}$ The most reliable methods are those addressed to study the molecular alterations that occur in early stage of tumor development. As a result of its many inconveniences, X-chromosome inactivation studies are far from ideal for assessing clonality. Although LOH pattern concordance in two separate carcinomas is highly suggestive of a common clonal origin (ie one tumor is a metastasis from the other), ${ }^{41-43}$ the finding of different LOH patterns does not necessarily indicate that they represent independent tumors. Some studies have shown varying LOH patterns in different areas of the same tumor as a consequence of tumor heterogeneity. ${ }^{43,44}$ Another weakness of this approach is that in the absence of informative markers and the failure to detect $\mathrm{LOH}$ it is likely to underestimate the frequency of clonality. Consequently, $\mathrm{LOH}$ analysis is not the best way to assess monoclonality in neoplasia; nevertheless, it may be useful if the possibility of tumor evolution is taken into consideration. Mutation analysis of certain genes involved in early stages of tumorigenesis is an excellent method for assessing the relation of the ovarian and endometrial carcinomas in cases of synchronous tumors. ${ }^{44-46}$ The comparative analyses have included microsatellite instability (MI), ${ }^{45,47}$ and CTNNB1 (Figure 17), ${ }^{45}$ K-ras, p53 ${ }^{43}$ and PTEN

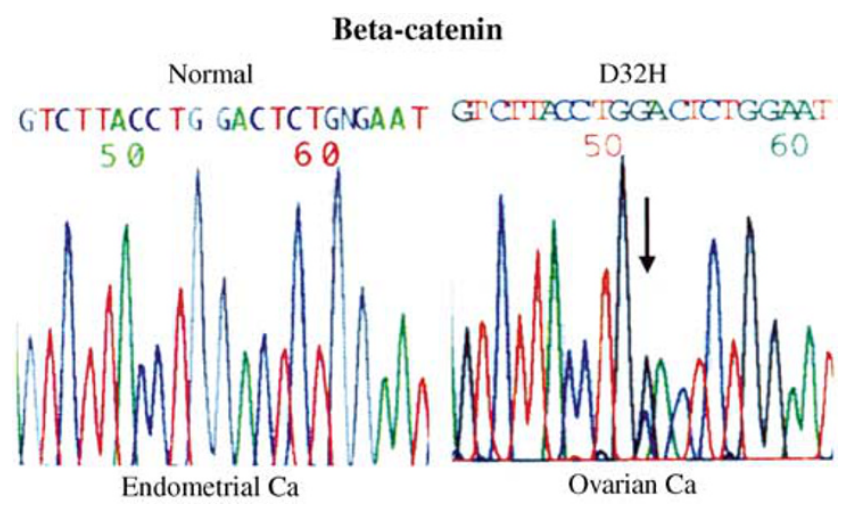

Figure 17 Simultaneous independent endometrioid adenocarcinomas of the endometrium and the ovary. DNA sequencing of exon 3 of the beta-catenin (CTNNB1) gene showing a GGA to GCA mutation at codon $32(\mathrm{D} 32 \mathrm{H})$ in the ovarian endometrioid adenocarcinoma. The change was not identified in the uterine endometrial adenocarcinoma (left) (Figure 7 from Matias-Guiu X et $a l^{41}$ ) Reproduced with permission of Lippincott, Williams \& Wilkins.

mutations. ${ }^{46}$ Although these methods may be useful in individual cases, their results should be interpreted with caution, and always in concordance with the clinicopathologic findings. Discordant gene mutations and different MI patterns in the two neoplasms are suggestive of independent primary carcinomas; ${ }^{44-46}$ nevertheless, metastatic carcinomas may also exhibit gene mutations that differ from those of their corresponding primary tumors as a result of tumor progression. ${ }^{44,48}$ Alternatively, two independent primary carcinomas may present identical gene mutations, reflecting induction of the same genetic abnormalities by a common carcinogenic agent acting in two separate sites of a single anatomic region. In other words, the genetic profile can be identical in independent tumors and different in metastatic carcinomas.

\section{Malignant Brenner tumor and transitional cell carcinoma}

Microscopically, malignant Brenner tumors are characterized by invasive transitional or squamous cell carcinoma, alone or mixed with each other, and a benign or borderline Brenner tumor component (Figure 18). ${ }^{49-52}$ Mucinous elements and, more rarely, mucinous adenocarcinoma may coexist with the transitional component. However, pure mucinous carcinomas associated with a benign Brenner tumor should not be diagnosed as a malignant Brenner tumor. Malignant Brenner tumors are bilateral in $12 \%$ of cases.

Transitional cell carcinomas (TCCs) do not differ from other high-grade ovarian carcinomas regarding stage (often high) and bilaterality (15\% of cases). ${ }^{53-56}$ TCCs resemble those occurring in the urinary tract and lack a benign or borderline Brenner tumor component. The tumor cells characteristically form 


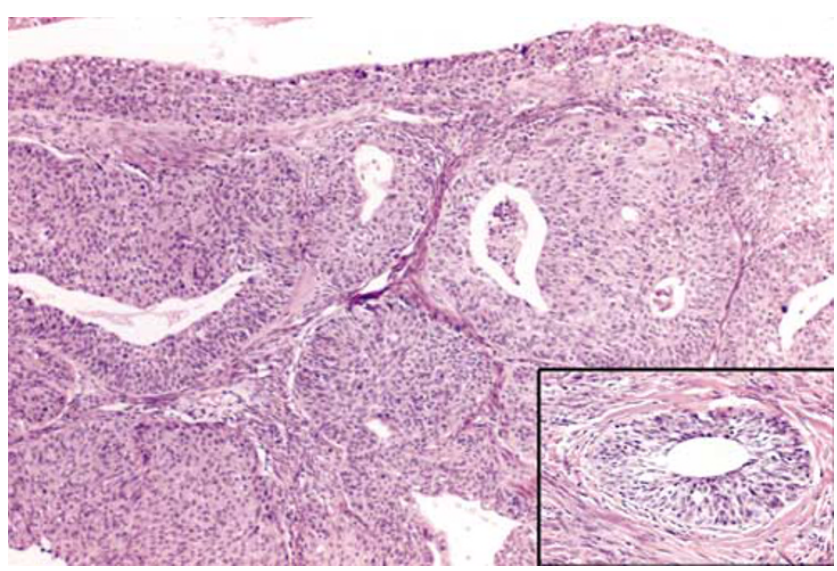

Figure 18 Malignant Brenner tumor. Large, closely packed, irregular aggregates of transitional cells infiltrate the stroma. Inset: nest of benign Brenner component found in the vicinity of a malignant Brenner tumor.

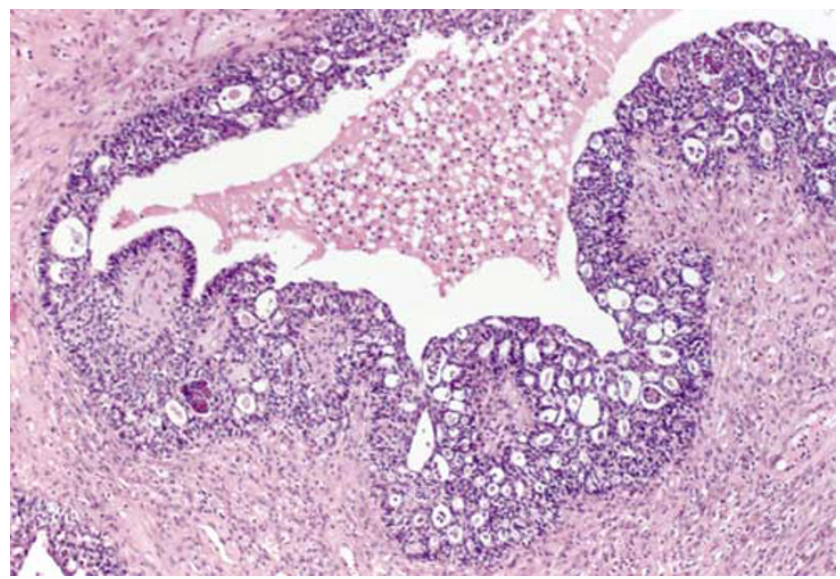

Figure 19 Transitional cell carcinoma. Compressed cyst lined by a thick layer of epithelial cells. Note the presence of intraepithelial microspaces (Figure 11-13 from Prat J. Pathology of the Ovary. Saunders: Philadelphia, 2004). Reproduced with permission.

undulating thick bands lining cysts (93\%) (Figure 19) or large papillae that protrude into empty spaces $(63 \%)$ (Figure 20). ${ }^{56}$ The cysts, which are often compressed, appear empty or contain cellular necrotic debris; the papillae have cores of fibrovascular tissue and show a smooth luminal border ('papillary type'). ${ }^{54-56}$ The bands of epithelium are multilayered, have a relative uniform width of at least a dozen cells, and typically contain microspaces of the size of or slightly larger than CallExner bodies (87\%). ${ }^{56}$ Diffuse (solid), insular, and trabecular patterns are encountered in approximately half of cases. Slit-like fenestrations or filiform papillae are seen focally in a minority of tumors. Tumor cell necrosis occurs in slightly over half of the cases. ${ }^{56}$ At low magnification, the tumor cells usually appear monomorphic and evenly spaced. The nuclei are round and often exhibit large, eosinophilic nucleoli, or longitudinal

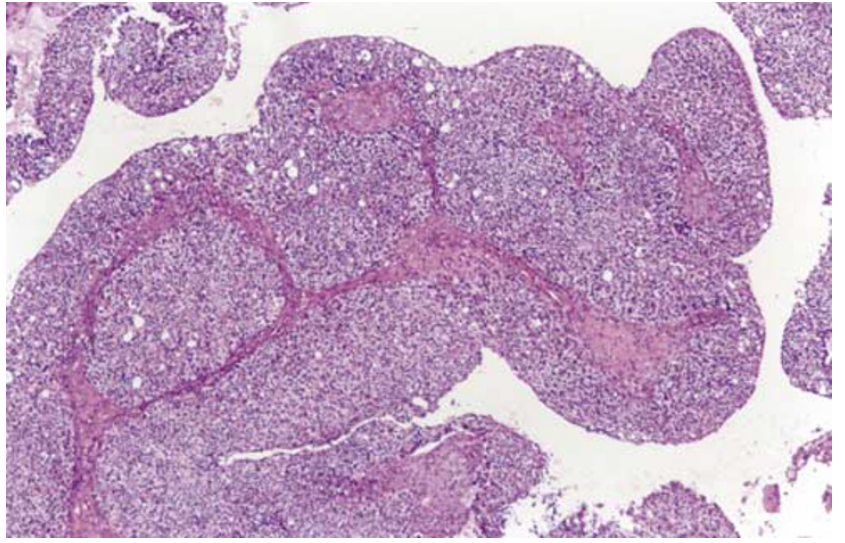

Figure 20 Transitional cell carcinoma. Multilayered papilla with smooth luminal borders protruding into an empty space (Figure 11-12 from Prat J. Pathology of the Ovary. Saunders: Philadelphia, 2004). Reproduced with permission.

grooves. ${ }^{56}$ The cytoplasm is moderately abundant and frequently pale and granular. Generally, the degree of nuclear atypicallity is moderate or marked and mitotic activity is high. As in urothelial carcinoma, glandular and/or squamous differentiation may occur. Unlike malignant Brenner tumors, transitional cell carcinomas are frequently associated or mixed with carcinomas of other types, usually poorly differentiated serous or endometrioid carcinomas. ${ }^{55,56}$

\section{Immunohistochemistry}

Ovarian TCCs have an immunoprofile that differs from TCCs of the urinary tract and resembles that of ovarian epithelial stromal tumors. ${ }^{57-59}$ Ovarian TCCs are negative for CK20, thrombomodulin, and uroplakin. Unlike bladder cancer, ovarian TCCs are positive for vimentin and CA125.

\section{Differential Diagnosis}

TCCs are distinguished from undifferentiated carcinomas by the presence of thick, undulating papillae with smooth luminal borders in contrast to the pseudopapillae secondary to tumor cell necrosis that may be present in undifferentiated carcinomas. Microspaces are also more frequent in TCC than in undifferentiated carcinomas. The tumor cells in TCCs have moderate cytoplasm, and in well-differentiated areas the nuclei have a distinctive 'urothelial' appearance with low cytoplasmic to nuclear ratios and nuclear grooves. ${ }^{56}$

The adult type of granulosa cell tumor (AGCT) with a diffuse pattern may also be considered in the differential diagnosis. However, the microspaces of TCC are different from Call-Exner bodies; the former are larger and more variable in size and, in contrast to the latter, their lumens are sharply demarcated 
from the surrounding epithelial cells. ${ }^{56}$ Also, the nuclei in TCC often have prominent nucleoli and high mitotic activity. Finally, the clinical and operative findings can be helpful. AGCTs are often associated with estrogenic manifestations, are unilateral in $95 \%$ of cases, and confined to the ovary (stage I) in $90 \%$ of the cases.

\section{Prognosis}

Most malignant Brenner tumors are stage I and have an excellent prognosis with an 88\% 5-year survival; about one-fifth, however, present with extraovarian spread and behave similarly to other ovarian cancers. ${ }^{53}$ Nevertheless, the prognosis of advanced stage malignant Brenner tumors was reported in one series to be better than that of transitional cell carcinomas. ${ }^{53}$ It has been reported that carcinomas with transitional cell differentiation in their metastases usually behave more favorably than poorly differentiated carcinomas of the other types, apparently due to their better response to chemotherapy. ${ }^{55}$ Other studies, however, have not confirmed these results. ${ }^{60}$ The overall 5-year survival rate for TCC is $35 \%$.

\section{Krukenberg tumor}

Krukenberg tumors are adenocarcinomas with a distinctive histologic appearance. They are traditionally perceived as composed of mucin-filled signet-ring cells associated with a striking proliferation of the ovarian stroma but many variations on this pattern are seen; ${ }^{61,62}$ signet-ring cells, although sometimes scant, are still definitional but a cellular stroma is not as requiring its presence would exclude otherwise typical tumors from the Krukenberg category. These tumors originate in the stomach in the vast majority of cases. Sometimes, the gastric cancer may be small and remains undetected for several years after oophorectomy. Much less frequently, the primary tumor is in the large intestine, breast, gallbladder, uterine cervix, appendix, or urinary bladder. In rare cases, the site of origin of the primary tumor is unknown and a diagnosis of 'primary Krukenberg tumor' has been proposed for those cases in which either the patient survives in good health for 10 years or longer or a thorough autopsy fails to reveal an extraovarian primary tumor. ${ }^{1}$ Possibly, some of the cases reported in the older literature as 'primary Krukenberg tumors' represent mucinous (goblet cell) carcinoids. ${ }^{63} \mathrm{~Pa}-$ tients with Krukenberg tumors tend to be younger than most patients with metastatic carcinoma; most of them are between 40 and 50 years of age. Although the symptoms are usually nonspecific, endocrine manifestations, such as virilization during pregnacy, may result from stromal luteinization. ${ }^{1}$

Krukenberg tumors are bilateral in at least $80 \%$ of the cases. ${ }^{1}$ They are typically solid masses with smooth nodular or bosselated outer surfaces. The cut surfaces are usually predominantly white or tan (Figure 21) with frequent areas of red or brown discoloration; the consistency may be firm, fleshy, or gelatinous. Because of the marked proliferation of the ovarian stroma, in some cases the tumors may resemble fibrothecomas on gross examination.

Microscopically, some tumors are composed of multiple, ill-defined, and coalescent nodules, a pattern common to various types of metastatic ovarian tumor. A more typical pattern is characterized by juxtaposition of compact areas containing tumor cells, stromal elements or both, and pale edematous zones. Frequently, a pseudocapsule of compact tumor is seen between the ovarian surface epithelium and the central edematous zone (Figure 22). ${ }^{62}$ The plump, rounded carcinoma cells often have a signet-ring appearance with vacuolated cytoplasm but some signet-ring cells have eosinophilic cytoplasm and some cells may appear nonspecific malignant cells. The epithelial cells may appear singly or in clusters (Figure 23). Small glands, some of them appearing as microcysts, are usually found, as are larger glands and, occasionally, there is a predominant tubular architecture (tubular Krukenberg tumor). ${ }^{61}$ The stromal cells are typically spindle shaped, and their degree of cellularity is variable, ranging from that of a normocellular ovarian fibroma to that of a cellular fibroma or fibrosarcoma to, conversely, that of an edematous fibroma. Some tumors are extensively luteinized. ${ }^{1,61}$

Krukenberg tumors must be distinguished from primary and other metastatic ovarian tumors that have mucin-rich signet-ring cells including clear cell adenocarcinoma, mucinous (goblet cell) carcinoid, and a variety of ovarian tumors that contain signet-ring-like cells filled with nonmucinous material. Ovarian clear cell adenocarcinoma may have

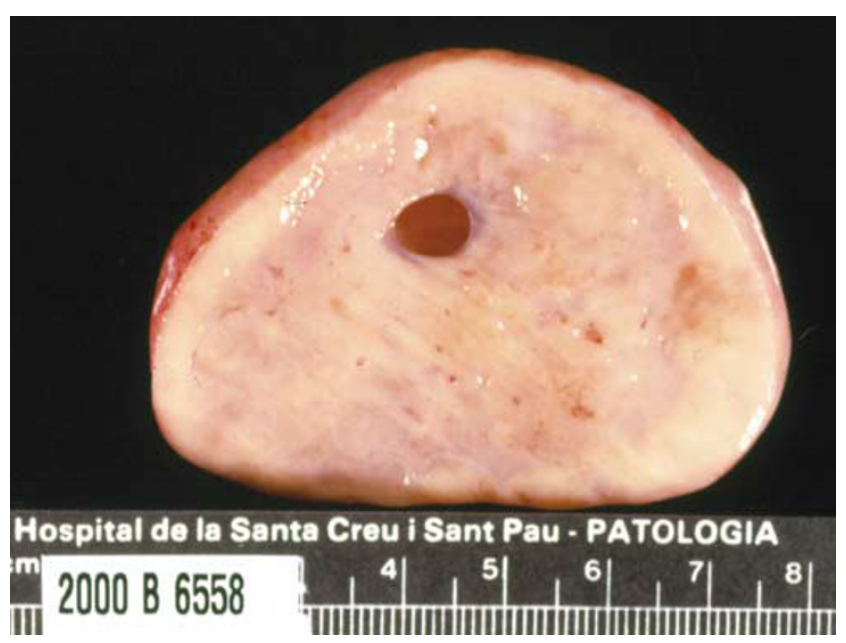

Figure 21 Krukenberg tumor. The cut surface is composed of solid pale-yellow tissue with focal pink discoloration (Figure 1815 from Prat J. Pathology of the Ovary. Saunders: Philadelphia, 2004). Reproduced with permission. 


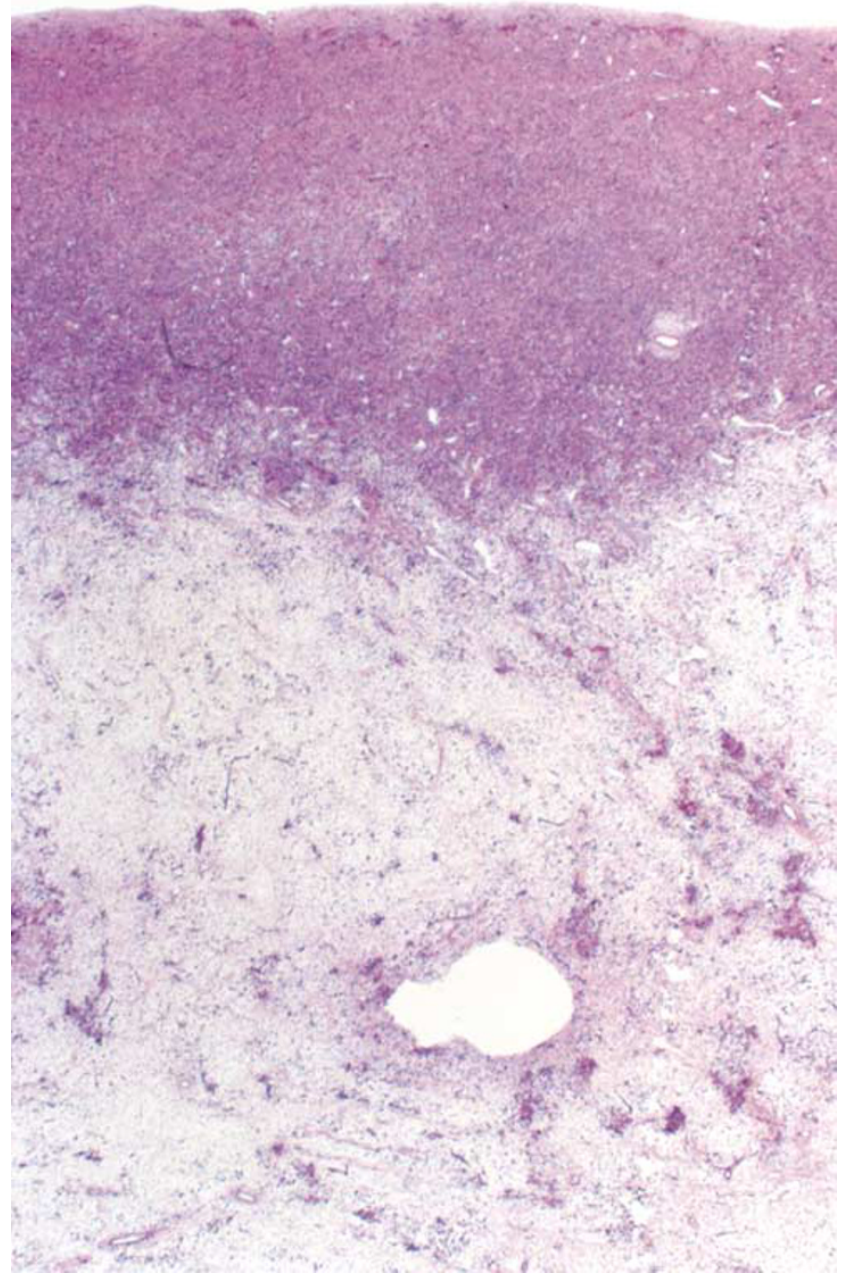

Figure 22 Krukenberg tumor. A band of compact tumor is seen between the ovarian surface epithelium (top) and the central edematous zone (bottom). (Figure 18-18 from Prat J. Pathology of the Ovary. Saunders: Philadelphia, 2004). Reproduced with permission.

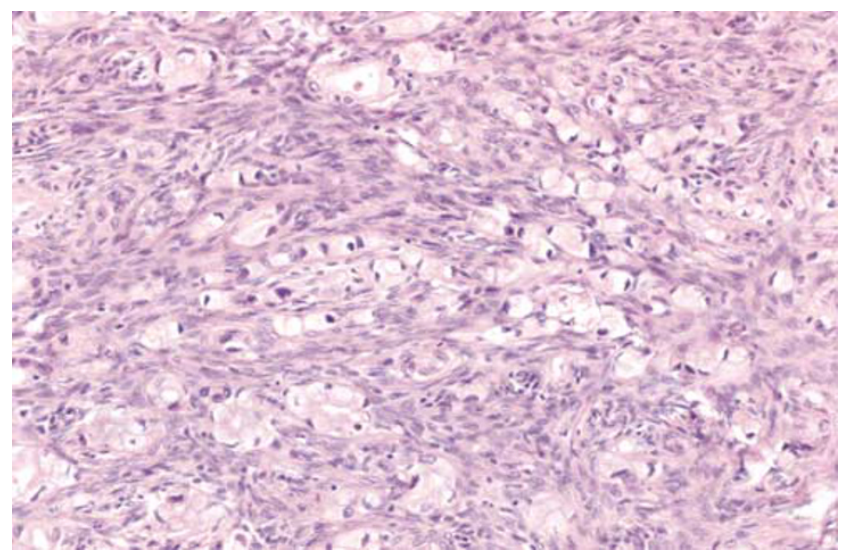

Figure 23 Krukenberg tumor. Numerous signet-ring cells with pale cytoplasm are arranged irregularly within a cellular stroma (Figure 18-16 from Prat J. Pathology of the Ovary. Saunders: Philadelphia, 2004). Reproduced with permission.

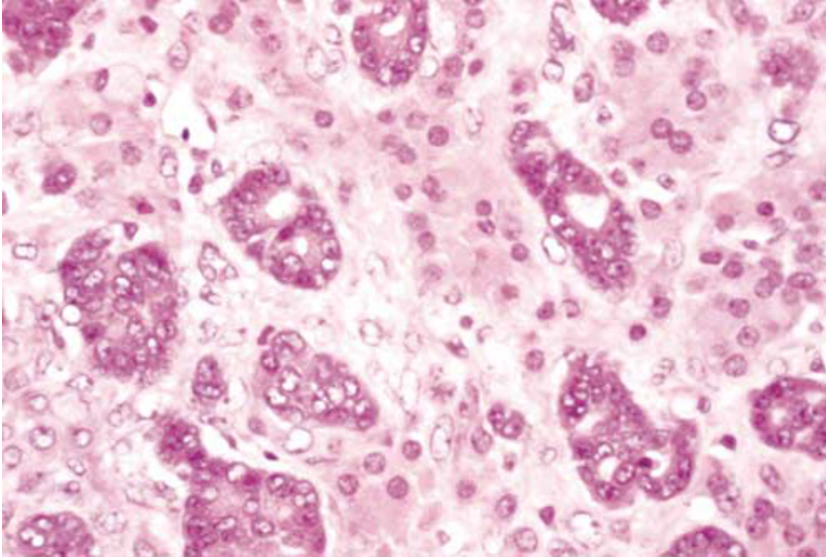

Figure 24 Tubular Krukenberg tumor. The tubular glands are lined by markedly atypical cells. The intertubular clusters of luteinized stromal cells contribute to the resemblance to a Sertoli-Leydig cell tumor (Figure 18-20 from Prat J. Pathology of the Ovary. Saunders: Philadelphia, 2004). Reproduced with permission.

a signet-ring cell component that simulates a Krukenberg tumor but the presence of the various distinctive patterns of clear cell carcinoma should resolve the problem. CK immunostains are not useful, as nearly half of gastric carcinomas metastatic to the ovary are CK7 positive/CK20 negative. ${ }^{25}$ Mucinous carcinoid, either primary or metastatic, may contain large areas of signet-ring cells; the former neoplasms, however, frequently contain other teratomatous elements, and Grimelius stains as well as immunostains for chromogranin and synaptophysin are usually positive in both.

The tubular variant of Krukenberg tumor, when associated with stromal luteinization, can be confused with a Sertoli-Leydig cell tumor (Figure 24); however, signet-ring cells are not a feature of the latter tumor except for the heterologous form that contains mucinous intestinal glands. ${ }^{61}$ Positive mucicarmine and PAS stains with diastase digestion, the latter being more reliable, are of great value in establishing the diagnosis of a Krukenberg tumor. Occasional Krukenberg tumors may closely resemble fibromas on macroscopic examination and may have relatively few signet-ring cells. Bilaterality and positive mucin stains facilitate the diagnosis.

\section{Acknowledgements}

This work was supported by Grant FIS PI02-0371, Department of Health, Spain.

\section{References}

1 Scully RE, Young RH, Clement PB. Tumors of the Ovary, Maldeveloped Gonads, Fallopian Tube, and Broad Ligament. Atlas of Tumor Pathology, Third 
Series, Fascicle 23. AFIP: Washington, DC, 1998, pp 81-105.

2 Lee K, Scully RE. Mucinous tumors of the ovary. A clinicopathologic study of 196 borderline tumors (of intestinal type) and carcinomas, including an evaluation of 11 cases with 'pseudomyxoma peritonei'. Am J Surg Pathol 2000;24:1447-1464.

3 Hoerl HD, Hart WR. Primary ovarian mucinous cystadenocarcinomas. A clinicopathologic study of 49 cases with long term follow-up. Am J Surg Pathol 1998;22:1449-1462.

4 Riopel MA, Ronnett BM, Kurman RJ. Evaluation of diagnostic criteria and behavior of ovarian intestinaltype mucinous tumors: atypical proliferative (borderline), tumors, and intraepithelial, microinvasive, invasive and metastatic carcinomas. Am J Surg Pathol 1999;23:617-635.

5 Shappell HW, Riopel MA, Smith Sehdev AE, et al. Diagnostic criteria and behavior of ovarian seromucinous (endocervical-type mucinous and mixed cell-type) tumors. Atypical proliferative (borderline) tumors, intraepithelial, microinvasive, and invasive carcinomas. Am J Surg Pathol 2002;26: 1529-1541.

6 Lee KR, Nucci MR. Ovarian mucinous and mixed epithelial carcinomas of mullerian (endocervical-like) type: a clinicopathologic analysis of four cases of an uncommon variant associated with endometriosis. Int J Gynecol Pathol 2003;22:42-51.

7 Young RH, Hart WR. Metastases from carcinomas of the pancreas simulating primary mucinous tumors of the ovary: a report of seven cases. Am J Surg Pathol 1989;13:748-756.

8 Young RH, Gilks CB, Scully RE. Mucinous tumors of the appendix associated with mucinous tumors of the ovary and pseudomyxoma peritonei: a clinicopathological analysis of 22 cases supporting an origin in the appendix. Am J Surg Pathol 1991;15:415-429.

9 Ji H, Isacson C, Seidman J, et al. Cytokeratins 7 and 20, Dpc4, and MUC5AC in the distinction of metastatic mucinous carcinomas in the ovary from primary ovarian mucinous tumors: Dpc4 assists in identifying metastatic pancreatic carcinomas. Int J Gynecol Pathol 2002;21:391-400.

10 Park SY, Kim HS, Hong EK, et al. Expression of cytokeratins 7 and 20 in primary carcinomas of the stomach and colorectum and their value in the differential diagnosis of metastatic carcinomas to the ovary. Hum Pathol 2002;33:1078-1085.

11 Lee KR, Young RH. The distinction between primary and metastatic mucinous carcinomas of the ovary: gross and histologic findings in 50 cases. Am J Surg Pathol 2003;27:281-292.

12 Rodríguez IM, Prat J. Mucinous tumors of the ovary. A clinicopathologic analysis of 75 borderline tumors (of intestinal type) and carcinomas. Am J Surg Pathol 2002;26:139-152.

13 Mok SC-H, Bell DA, Knapp RC, et al. Mutation of K-ras protooncogene in human ovarian epithelial tumors of borderline malignancy. Cancer Res 1993;53: 1489-1492.

14 Cuatrecasas M, Villanueva A, Matias-Guiu X, et al. K-ras mutations in mucinous ovarian tumors. A clinicopathologic and molecular study of 95 cases. Cancer 1997;79:1581-1586.

15 Mandai M, Konishi I, Kuroda H, et al. Heterogeneous distribution of K-ras-mutated epithelia in mucinous ovarian tumors with special reference to histopathology. Hum Pathol 1998;28:34-40.

16 Nomura K, Aizawa S. Noninvasive, microinvasive, and invasive mucinous carcinomas of the ovary. A clinicopathologic analysis of 40 cases. Cancer 2000;89: 1541-1546.

17 Prat J, Scully RE. Ovarian mucinous tumors with sarcoma-like mural nodules. Cancer 1979;44:13321344.

18 Prat J, Young RH, Scully RE. Ovarian mucinous tumors with foci of anaplastic carcinoma. Cancer 1982;50: 300-304.

19 Prat J, Scully RE. Sarcomas in ovarian mucinous tumors. Cancer 1979;44:1327-1331.

20 Bagué S, Rodríguez I, Prat J. Sarcoma-like mural nodules in mucinous cystic tumors of the ovary revisited. A clinicopathologic analysis of 10 additional cases. Am J Surg Pathol 2002;26:1467-1476.

21 Fujii S, Konishi J, Kobayashi F. Sarcoma-like mural nodules combined with a microfocus of anaplastic carcinoma in mucinous ovarian tumor. Gynecol Oncol 1985;20:219-233.

22 Provenza C, Prat J, Young RH. Foci/nodules of anaplastic carcinoma in mucinous cystic ovarian tumors: a clinicopathologic study of 34 cases (Abstract). Mod Pathol 2004;17:211A.

23 Berezowski K, Stastny JK, Kornstein MJ. Cytokeratins 7 and 20 and carcinoembryonic antigen in colonic and ovarian carcinoma. Mod Pathol 1996;9:426-429.

24 DeCostanzo DC, Elias JM, Chumas JC. Necrosis in 84 ovarian carcinomas: a morphologic study of primary versus metastatic colonic carcinoma with a selective immunohistochemical analysis of cytokeratin subtypes and carcinoembryonic antigen. Int J Gynecol Pathol 1997;16:245-249.

25 Wang NP, Zee S, Zarbo RJ, et al. Coordinate expression of cytokeratins 7 and 20 defines unique subsets of carcinomas. Appl Immunohistochem 1995;3: 99-107.

26 Wauters CCAP, Smedts F, Gerrits LGM, et al. Keratins 7 and 20 as diagnostic markers of carcinomas metastatic to the ovary. Hum Pathol 1995;26:852-855.

27 Dabbs DJ, Sturtz K, Zaino RJ. The immunohistochemical discrimination of endometrioid carcinomas. Hum Pathol 1996;27:172-177.

28 Cheung ANY, Chiu PM, Khoo US. Is immunostaining with HAM56 antibody useful in identifying ovarian origin of metastatic adenocarcinomas? Hum Pathol 1997;28:91-94.

29 Lash RH, Hart WR. Intestinal adenocarcinomas metastatic to the ovaries: a clinicopathologic evaluation of 22 cases. Am J Surg Pathol 1987;11:114-121.

30 Young RH, Hart WR. Metastatic intestinal carcinomas simulating primary ovarian clear cell carcinoma and secretory endometrioid carcinoma: a clinicopathologic and immunohistochemical study of five cases. Am J Surg Pathol 1998;22:805-815.

31 Young RH, Prat J, Scully RE. Ovarian endometrioid carcinomas resembling sex cord-stromal tumors. A clinicopathologic analysis of 13 cases. Am J Surg Pathol 1982;6:513-522.

32 Roth LM, Liban E, Czernobilsky B. Ovarian endometrioid tumors mimicking Sertoli and Sertoli-Leydig cell tumors. Sertoliform variant of endometrioid carcinoma. Cancer 1982;50:1322-1331.

33 Ordi J, Schammel DP, Rasekh L, et al. Sertoliform endometrioid carcinomas of the ovary: a clinicopatho- 
logic and immunohistochemical study of 13 cases. Mod Pathol 1999;12:933-940.

34 Matias-Guiu X, Pons C, Prat J. Mullerian inhibiting substance, alpha-inhibin, and CD99 expression in sex cord-stromal tumors and endometrioid ovarian carcinomas resembling sex cord-stromal tumors. Hum Pathol 1998;29:840-845.

35 Aguirre P, Thor AD, Scully RE. Ovarian endometrioid carcinomas resembling sex cord-stromal tumors. An immunohistochemical study. Int J Gynecol Pathol 1989;8:364-373.

36 Eifel P, Hendrickson M, Ross J, et al. Simultaneous presentation of carcinoma involving the ovary and the uterine corpus. Cancer 1982;50:163-170.

37 Zaino RJ, Unger ER, Whitney C. Synchronous carcinomas of the uterine corpus and ovary. Gynecol Oncol 1984;19:329-335.

38 Ulbright TM, Roth LM. Metastatic and independent cancers of the endometrium and ovary: a clinicopathologic study of 34 cases. Hum Pathol 1985;16:28-34.

39 Prat J, Matias-Guiu X, Barreto J. Simultaneous carcinoma involving the endometrium and the ovary. A clinicopathologic, immunohistochemical, and DNA flow cytometric study of 18 cases. Cancer 1991;68: 2455-2459.

40 Smith VTHBM, Cornelisse CJ, De Jong D, et al. Analysis of tumor heterogeneity in a patient with synchronously occurring female genital tract malignancies by DNA flow cytometry: DNA fingerprint and immunohistochemistry. Cancer 1988;62:1146-1152.

41 Matias-Guiu X, Lagarda H, Catasus LL, et al. Clonality analysis in synchronous and metachronous tumors of the female genital tract. Int J Gynecol Pathol 2002;21: 205-211.

42 Prat J. Clonality analysis in synchronous tumors of the female genital tract (Editorial). Hum Pathol 2002;33: 383-385.

43 Fujita M, Enomoto T, Wada H, et al. Application of clonal analysis. Differential diagnosis for synchronous primary ovarian and endometrial cancers and metastatic cancer. Am J Clin Pathol 1996;105:350-359.

44 Fujii H, Matsumoto T, Yoshida M, et al. Genetics of synchronous uterine and ovarian endometrioid carcinoma: combined analysis of loss of heterozygosity, PTEN mutation, and microsatellite instability. Hum Pathol 2002;33:421-428.

45 Moreno-Bueno G, Gamallo C, Perez-Gallego L, et al. Beta-catenin expression pattern, beta-catenin gene mutations, and microsatellite instability in endometrioid ovarian carcinomas and synchronous endometrial carcinomas. Diagn Mol Pathol 2001;10:116-122.

46 Lin WM, Forgacs E, Warshal DP, et al. Loss of heterozygosity and mutational analysis of the PTEN/ MMAC1 gene in synchronous endometrial and ovarian carcinomas. Clin Cancer Res 1998;4:2577-2583.

47 Shenson DL, Gallion HH, Powell DE, et al. Loss of heterozygosity and genomic instability in synchronous endometrioid tummors of the ovary and endometrium. Cancer 1995;76:650-657.

48 Matias-Guiu X, Bussaglia E, Catasus LL, et al. Loss of heterozygosity and mutational analysis of the PTEN/ MMAC1 gene in synchronous endometrial and ovarian carcinomas (Letter to the editor). Clin Cancer Res 2000;6:1598-1600.

49 Hallgrimsson J, Scully RE. Borderline and malignant Brenner tumours of the ovary. A report of 15 cases. Acta Path Microbiol Scand (A) 1972;80(Suppl 233): 56-66.

50 Miles PA, Norris HJ. Proliferative and malignant Brenner tumors of the ovary. Cancer 1972;30:174-186.

51 Woodruff JD, Dietrich D, Genadry R, et al. Proliferative and malignant Brenner tumors. Review of 47 cases. Am J Obstet Gynecol 1981;41:118-125.

52 Roth LM, Czernobilsky B. Ovarian Brenner tumors. II. Malignant. Cancer 1985;56:592-601.

53 Austin RM, Norris HJ. Malignant Brenner tumor and transitional cell carcinoma of the ovary: a comparison. Int J Gynecol Pathol 1987;6:29-39.

54 Roth LM, Gersell DJ, Ulbright TM. Ovarian Brenner tumors and transitional cell carcinoma: recent developments. Int J Gynecol Pathol 1993;12:128-133.

55 Silva EG, Robey-Cafferty SS, Smith TL, et al. Ovarian carcinomas with transitional cell carcinoma pattern. Am J Clin Pathol 1990;93:457-465.

56 Eichhorn JH, Young RH. Transitional cell carcinoma of the ovary. A morphologic study of 100 cases with emphasis on differential diagnosis. Am J Surg Pathol 2004;28:453-463.

57 Soslow RA, Rouse RV, Hendrickson MR, et al. Transitional cell neoplasms of the ovary and urinary bladder: a comparative immunohistochemical analysis. Int J Gynecol Pathol 1996;15:257-265.

58 Ordonez NG. Transitional cell carcinomas of the ovary and bladder are immunophenotypically different. Histopathology 2000;36:433-438.

59 Logani S, Oliva E, Amin MB, et al. Immunoprofile of ovarian tumors with putative transitional cell (urothelial) differentiation using novel urothelial markers: histogenetic and diagnostic implications. Am J Surg Pathol 2003;27:1434-1441.

60 Hollingsworth HC, Steinberg SM, Silverberg SG, et al. Advanced stage transitional cell carcinoma of the ovary. Hum Pathol 1996;27:1267-1272.

61 Bullón A, Arseneau J, Prat J, et al. Tubular Krukenberg tumor. A problem in histopathologic diagnosis. Am J Surg Pathol 1981;5:225-232.

62 Kiyokawa T, Young RH, Scully RE. Krukenberg tumors of the ovary: a clinicopathologic analysis of 120 cases with emphasis on their variable pathological manifestations (in preparation).

63 Baker PM, Oliva E, Young RH, et al. Ovarian mucinous carcinoids including some with a carcinomatous component. A report of 17 cases. Am J Surg Pathol 2001;25:557-568. 